\title{
O impeachment presidencial de 2015 pelos olhos da ciência da informação: a categorização dos temas contidos nos discursos dos deputados federais
}

\author{
Thiago Gomes Eirão \\ Câmara dos Deputados, Centro de Documentação e Informação, Brasília, DF, Brasil \\ thiagoe@gmail.com
}

DOI: $\underline{\text { https://doi.org/10.26512/rici.v13.n3.28674 }}$

Recebido/Recibido/Received: 2019-12-16

Aceitado/Aceptado/Accepted: 2020-07-22

Resumo: Trata da caracterização temática dos votos proferidos pelos deputados federais durante a sessão de votação na Câmara dos Deputados que aceitou a abertura do processo de impeachment da presidente da República Dilma Rousseff em 2015. Após o processo de votação houve críticas quanto ao conteúdo dos votos dos parlamentares por conterem excessivas citações a familiares e motivações particulares em detrimento do interesse público. Com o intuito de investigar os itens informacionais representantes dos votos, essa pesquisa teve como foco compreender os temas que sustentaram cada voto, além de averiguar se as críticas são procedentes. O objetivo central foi identificar, a partir dos discursos proferidos, o contexto informacional e assim determinar os itens-chave temáticos de cada voto proferido. A partir de uma abordagem qualitativa, utilização dos princípios da similaridade, diferenças, relação de sinonímia e tendo como objeto empírico de estudo as notas taquigráficas individuais de cada discurso proferido pelos parlamentares, foi possível criar cinco macro categorias para agrupamento dos itens-chave identificados. Foram identificados 1.348 itens-chave citados pelos parlamentares como identificadores dos discursos. Dividindo-se esse número pelo total de votantes, 504 deputados, chega-se à média de quase três itenschave específicos por voto. Os dados coletados demonstram que na retórica parlamentar durante a manifestação de votos, o item-chave caracterizador mais recorrente nos votos, sejam eles a favor ou contra, foi "povo brasileiro".

Palavras-chave: Caracterização temática. Discurso político. Impeachment. Câmara dos Deputados.

La acusación presidencial de $\mathbf{2 0 1 5}$ para los ojos de la ciencia de la información: la categorización de temas contenidos por los diputados federales.

Resumen: Se trata de la caracterización temática de los votos realizados por los diputados federales durante la sesión de votación en la Cámara de Diputados que aceptaron la apertura del proceso de juicio político de la Presidenta de la República, Dilma Rousseff, en 2015. Después del proceso de votación hubo críticas sobre el contenido de los votos de los parlamentarios. por contener citas excesivas a miembros de la familia y motivaciones particulares en detrimento del interés público. Para investigar los elementos de información que representan los votos, esta investigación se centró en comprender los temas que respaldaron cada voto, además de determinar si las críticas son válidas. El objetivo central era identificar, a partir de los discursos pronunciados, el contexto informativo y así determinar los elementos temáticos clave de cada voto emitido. Desde un enfoque cualitativo, utilizando los principios de similitud, diferencias, relación de sinónimos y teniendo las notas abreviadas individuales de cada discurso pronunciadas por los parlamentarios como objeto de estudio empírico, fue posible crear cinco categorías macro para agrupar los elementos clave identificados. Se identificaron 1.348 elementos clave, citados por parlamentarios como identificadores de discursos. Dividiendo este número por el número total de votantes, 504 diputados, se alcanza el promedio de casi 3 elementos clave específicos por voto. Los datos recopilados muestran que en la retórica parlamentaria durante el proceso de votación, el elemento clave 
que caracteriza a los votos más recurrentes, ya sea a favor o en contra, fue el "pueblo brasileño".

Palabras clave: Caracterización temática. Discurso político. Juicio político. Camara de los Diputados.

The $\mathbf{2 0 1 5}$ presidential impeachment for the eyes of information science: the categorization of themes in the speech of the federal members

Abstract: It deals with the thematic characterization of the votes made by federal deputies during the voting session in the Chamber of Deputies that accepted the opening of the impeachment process of the President of the Republic Dilma Rousseff in 2015. After the voting process, there were criticisms regarding the content of the votes of the parliamentarians for containing excessive citations to family members and particular motivations to the detriment of the public interest. To investigate the information items representing votes, this research focused on understanding the themes that supported each vote, in addition to ascertaining whether the criticisms are valid. The central objective was to identify, from the speeches made, the informational context and thus determine the key thematic items of each vote cast. From a qualitative approach, using the principles of similarity, differences, synonymy relationship and having as empirical object of study the individual shorthand notes of each speech given by parliamentarians, it was possible to create five macro categories for grouping the identified key items. 1,348 key items were identified, cited by parliamentarians as identifiers of speeches. Dividing this number by the total number of voters, 504 deputies, the average of almost 3 specific key items per vote is reached. The data collected show that in the parliamentary rhetoric during the voting process, the key item that characterizes the most recurring votes, whether for or against, was the "Brazilian people".

Keywords: Thematic characterization. Political speech. Impeachment. Chamber of Deputies.

\section{Introdução}

A história da sociedade moderna foi construída por meio de embates físicos e de ideais, que se alternaram como a arena de resolução de conflitos ao longo do tempo. De maneira análoga, a forma de organização do Estado passou por inúmeras transformações desde a centralização na figura de uma pessoa tal como um rei ou ditador, até o paradigma atualmente vigente que reside na pluralidade e dispersão do poder a partir de múltiplos atores com poderes e atribuições limitadas, escolhidos mediante a manifestação e decisão da maioria de uma sociedade, algo que podemos denominar como um dos pilares da democracia (GALVÃO; MEFFE, 2010). De acordo com Tocqueville (2010, p. 51), a democracia " [...] constitui o estado social, a lei das leis que determina o direito político". De maneira sucinta, a democracia é o sistema político que colocou a vontade do coletivo acima de ações e interesses individuais e permitiu a alternância de poder por meios mais racionais e seguros para a sociedade.

Designando bem menos um regime político que um modelo de sociedade que corresponde a um tipo de mentalidade, ela [democracia] se situa, em sua própria essência e desde sempre, sob o signo da ambivalência. Rica em esperanças, a democracia é para o homem uma promoção política: em sua marcha lenta, ela demarcou a conquista da liberdade dos povos e tornou possível o reconhecimento dos direitos do homem. (GOYARD-FABRE, 2003, p. 1).

Baseados nos princípios da distribuição de poder, sufrágio universal, alternância de representantes e liberdades coletivas e individuais, os regimes democráticos proliferaram em todos os continentes, alguns de maneira tardia ou de maneira superficial, mas mesmo assim, se tornaram o modelo de regime ideal a ser seguido na sociedade moderna. Embora amplamente 
difundida como um valor, a democracia segundo Bobbio (1996), não é usurpada para sempre muito menos concedida para sempre, ela é o resultado de embates de forças e a história da humanidade pode ser resumida como "[...] uma trama dramática de liberdade e de opressão" (BOBBIO, 1996, p. 75).

No contexto brasileiro a democracia ainda está a construir sua história já que, após mais de duas décadas de ditadura militar (1964-1985), o regime democrático foi apenas recentemente restaurado na realidade do Brasil (FAUSTO, 2014). Retomada em 1985, sob o regime presidencialista, a democracia brasileira logo em seus primeiros anos já seria testada política e economicamente, especialmente por denúncias de corrupção envolvendo o chefe do Poder Executivo.

Em 1990, Fernando Collor de Mello elegeu-se Presidente do Brasil com a promessa de renovação política e de dias melhores para a nação. No entanto, logo em seus primeiros anos de mandato, denúncias de corrupção e desvio de verba pública colocaram seu governo em dúvida, situação que se agravou e culminou no primeiro impeachment de um presidente do Brasil, em 1992. (BRASIL, 1992).

Impeachment, segundo Mendes e Branco (2016), é o processo instaurado com base em denúncia de crime de responsabilidade contra alta autoridade do Poder Executivo e cabe ao Poder Legislativo julgar e proferir a sentença. Os crimes de responsabilidade estão previstos no art. 85 da Constituição Federal (BRASIL, 1988) e descritos de maneira mais específica na Lei no 1.079, de 10 de abril de 1950. De acordo com essas normas, cabe à Câmara dos Deputados o recebimento da denúncia e parecer ante a sua procedência ou não. Havendo procedência, é decretada a acusação que passa a ser deliberada e julgada pelo Senado Federal.

O processo de julgamento no Senado Federal é conduzido pelo presidente do Supremo Tribunal Federal e produz efeitos assim que a sentença é proferida. Submetido a todo esse rito, Fernando Collor de Mello foi retirado do cargo entrando para a história como primeiro presidente da República a sofrer o processo de impeachment.

Em abril de 2015, 23 anos após a finalização do processo de impeachment de Fernando Collor de Mello, a questão volta ao centro do debate político com o acolhimento da denúncia contra a presidente Dilma Rousseff por crime de responsabilidade dando início a um novo capítulo da história política brasileira que julgou novamente se um presidente cometeu crime de responsabilidade e se deveria, portanto, perder seu cargo (BRASIL, 2016).

O processo de impeachment segundo Galuppo (2016) é político-jurídico, sendo sua análise permeada não apenas por detalhes legais, mas sim, pelo embate ideológico presente nas bancadas parlamentares que compõem o Congresso Nacional. Soma-se a isso, o fenômeno comunicacional e informacional envolvido em um processo de impeachment, que, 
massivamente, toma conta da agenda dos meios de comunicação e de maneira similar repercute fortemente em toda sociedade. Exatamente na intersecção desses conceitos, política, informação e comunicação, que a Ciência da Informação encontra acolhida no estudo da informação produzida e registrada no processo de impeachment presidencial, um fenômeno com grandes implicações sociais.

De acordo com Le Coadic (2004, p. 26) a Ciência da Informação é uma "[...] ciência social rigorosa [...]. Tem por objetivo o estudo das propriedades gerais da informação (natureza, gênese, efeitos)". Em outras palavras, uma ciência que analisa os processos de construção, comunicação e uso da informação (LE COADIC, 2004). Sendo os processos de comunicação e uso da informação cada vez complexos, e, havendo "um descompasso entre o que é desenvolvido em Representação Descritiva em relação à agenda de pesquisa em Recuperação da Informação (MORENO, 2015, p, 96), a Ciência da Informação depara-se com desafios amplos na caracterização desses processos informacionais, especialmente no contexto dos discursos políticos.

Segundo Pinto (2006, p. 89) o discurso político "é o discurso do sujeito por excelência", logo o indivíduo e sua realidade são os itens basilares para a construção desse instrumento de comunicação. Ainda segundo o autor, a característica fundamental do discurso político é que este necessita para sua sobrevivência impor a sua verdade a muitos e, ao mesmo tempo, é o que está mais ameaçado de não conseguir.

É o discurso cuja verdade está sempre ameaçada em um jogo de significações. Ele sofre cotidianamente a desconstrução, ao mesmo tempo só se constrói pela desconstrução do outro. É, portanto, dinâmico, frágil e, facilmente, expõe sua condição provisória. (PINTO, 2006, p. 89).

De maneira complementar, Orlandi (2007) afirma ser perigoso analisar o discurso político de forma fria ou desassociada de seu contexto já que pode levar a um entendimento equivocado sobre a questão central a ser comunicada. Perante o grande impacto informacional gerado pelo processo de impeachment, o papel do Poder Legislativo na sociedade moderna e tendo como fundamento o fluxo da informação como fator de poder (MACIEL; ALBAGLI, 2011), o presente trabalho tem como finalidade apresentar o contexto informacional que permeou a decisão de cada parlamentar por meio de uma proposta de categorização dos assuntos ou temas contidos nos discursos políticos proferidos na sessão da Câmara dos Deputados que autorizou a abertura do processo de impeachment da presidente Dilma Rousseff em 2015.

\section{Categorização de assuntos}

Categorizar, dentre outras acepções, significa organizar um conjunto de itens com determinada finalidade ou interesse. Segundo Baptista $(2015$, p. 21), o registro textual é, em si, 
um instrumento de organização e representação da informação contida nele, já que se configura como "[...] portador de significados úteis à disseminação de conteúdos e à construção do conhecimento". No contexto da Ciência da Informação, existem disciplinas e instrumentos específicos que trabalham com o processo de categorização de conteúdos com o objetivo de representar e disseminar a informação a partir de um arranjo mais inteligível ou útil para o público a que se destina. Tem-se como exemplos a classificação (LANGRIDGE, 2006; SOUZA, 2012) e a indexação de assuntos (LANCASTER, 2004).

Especificamente sobre a disciplina de indexação de assuntos, pode-se defini-la como o conjunto de ações com o intuito de traduzir determinado documento a partir de "itens-chave" para facilitar o entendimento de seu conteúdo, sendo assim uma importante ferramenta para a representação da informação para posterior recuperação (ROWLEY, 2002). A definição de diversos "itens-chave" pode conduzir a um ou mais agrupamentos temáticos, que por sua vez podem ser desmembrados em outras categorias temáticas específicas e assim sucessivamente. Dessa maneira é constituído um arranjo de assuntos, uma forma de compreensão do documento, através de categorias temáticas hierarquizadas também conhecidas como taxonomias (MOREIRO GONZÁLEZ, 2011).

O homem distingue tudo a sua volta pelas semelhanças e diferenças. Assim, aglomera os elementos com características similares criando formas de organização. É praticamente inerente ao ser humano organizar por afinidades, pois facilita não apenas maior entendimento, mas permite a criação de denominações para os conjuntos, originando categorizações e classificações (SCHIESSL; SHINTAKU, 2012, p. 80).

Sobre o processo de construção de categorias cabe ressaltar que qualquer forma de arranjo não é uma constante matemática, ou seja, é um processo objetivo-subjetivo onde a criação de determinada categoria é embasada em parte por uma teoria, que guia o processo de decisão, e parte pela opção própria do indivíduo em ser mais ou menos abrangente sobre o assunto. Nesse aspecto, Carlomagno e Rocha (2016, p. 178) afirmam que no campo objetivo existem quatro "regras lógicas" para a criação de categorias quando se faz a análise de conteúdo. São elas:

Regra 1: Devem ser claras, formais, objetivas e inscritas as decisões de inclusão e exclusão nas categorias; Regra 2: As categorias precisam ser mutuamente excludentes (exclusividade);

Regra 3: As categorias não podem ser muito amplas. Ou: não coloque coisas diferentes no mesmo saco (Homogeneidade); Regra 4: As categorias devem contemplar todos os conteúdos possíveis, e "outro" precisa ser residual (exaustividade) (CARLOMAGNO e ROCHA 2016, p. 178).

Já no campo subjetivo da decisão da construção de categorias, Lima (2010, p. 110), ao afirmar que por ser um processo cognitivo oriundo "[...] de nossa interação com o ambiente. Se nós não interagirmos com o ambiente, nós não teremos o que classificar [...]", é o ambiente em 
que o indivíduo está inserido o fator preponderante para a definição e existência das categorias que servem para "refletir o ponto de vista de uma informação em determinado contexto" (LIMA, 2010, p. 110). Logo a proposta de categorização apresentada neste trabalho sobre um tema complexo e que pode ser observado a partir de várias perspectivas, não se esgota em si ou tenta ser uma verdade absoluta sobre a questão, mas é sim, uma tentativa de observar um fenômeno político-social histórico para o Brasil, sob o viés da informação como requisito de produção de conhecimento.

Diante do exposto e partindo da mesma premissa de Araújo Júnior (2007, p. 14) que “[...] a análise de um documento é uma significativa contribuição para a comunicação e o fluxo de informação [...]", a categorização da informação de um discurso político, um documento complexo, com múltiplas finalidades e de alto impacto social (CHARAUDEAU, 2013) se configura como uma ação importante para permitir que a sociedade possa ser mais ativa dentro das estruturas do Estado e permitir a compreensão da dialética política que por muito tempo é apontada como um empecilho para a cidadania e transparência pública.

\section{0 processo de impeachment de Dilma Rousseff}

Eleita com 51,64\% dos votos válidos, perfazendo um total de 54.501 .118 votos (BRASIL, 2014), em uma das eleições mais disputadas da história brasileira, Dilma Rousseff enfrentaria logo no início do seu novo mandato, crises que mudariam drasticamente seus planos de governo.

Dilma era candidata da "Coligação com a força do povo", uma coligação partidária ampla com partidos de direita e esquerda, formada por seu partido, o Partido dos Trabalhadores (PT), Partido do Movimento Democrático do Brasil (PMDB), Partido Social Democrático (PSD), Partido Progressista (PP), Partido da República (PR), Partido Republicano da Ordem Social (PROS), Partido Democrático Trabalhista (PDT), Partido Comunista do Brasil (PC do B) e Partido Republicano Brasileiro (PRB). A candidatura à vice-presidência da chapa coube à Michel Temer do PMDB.

Ainda em 2014, durante a campanha eleitoral, Dilma se viu ameaçada por denúncias sobre o escândalo de compra de votos conhecido como Mensalão (REALE JÚNIOR, 2015) iniciado ainda no mandato de seu antecessor Luiz Inácio Lula da Silva e a operação deflagrada pelo Ministério Público conhecida como Lava-Jato (BARROS, 2016) que descobriu o esquema de desvio de verbas da Petrobras e outras instituições públicas.

Nesse ambiente instável e hostil, Dilma se elegeu. O primeiro ano de mandato avançou entre explicações e tentativas de acobertar os indícios que atormentavam a saúde e idoneidade de sua administração. Até que em 3 de dezembro de 2015, o então presidente da Câmara dos 
Deputados, Deputado Eduardo Cunha anunciou o acolhimento do segundo pedido de impeachment contra Dilma Rousseff impetrado pelos juristas Hélio Pereira Bicudo, Miguel Reale Júnior, Janaína Conceição Paschoal e Flávio Henrique Costa Pereira.

No documento apresentado, os juristas sustentavam que a presidente cometeu crimes de responsabilidade ao editar decretos de crédito extraordinário sem autorização do Congresso além da obtenção de crédito de forma irregular conhecida como "pedaladas fiscais"

Diz-se que essas operações de crédito ocorreram em governos passados. Não é verdade. Nunca antes, na história do Brasil, houve volume e quantidade extraordinários, por tempos tão longos, de operações de crédito, como um cheque especial, que foi sendo feito pelo governo junto às instituições financeiras que ele controla. E se maquiando isso, artificiosamente, fazendo de conta que esses débitos não existiam. E esses débitos junto ao Banco do Brasil, ao Fundo de Garantia e ao BNDES alcançam o valor extraordinário de R\$ 53 bilhões, em 2015. (BICUDO et al., 2015).

Com a decisão do Presidente da Câmara dos Deputados foi desencadeado todo o processo que culminou no impeachment de Dilma Rousseff no ano de 2016. De forma sucinta, apresenta-se, no Quadro 1 a cronologia e os fatos ocorridos tanto na Câmara dos Deputados quanto no Senado Federal sobre o processo de impeachment.

Quadro 1 - Cronologia do impeachment

\begin{tabular}{|l|l|}
\hline \multicolumn{1}{|c|}{ DATA } & \multicolumn{1}{c|}{ FATO } \\
\hline $03 / 12 / 2015$ & $\begin{array}{l}\text { O presidente da Câmara dos Deputados, Eduardo Cunha, comunica sua decisão de } \\
\text { aceitar a denúncia que pede abertura de processo de impeachment da presidente da } \\
\text { República. }^{1}\end{array}$ \\
\hline $03 / 12 / 2015$ & $\begin{array}{l}\text { O presidente da Câmara dos Deputados, Eduardo Cunha, cria Comissão Especial para } \\
\text { analisar pedido de impeachment. }\end{array}$ \\
\hline $17 / 03 / 2016$ & $\begin{array}{l}\text { Comissão Especial elege seus membros, seu presidente e relator para analisar o } \\
\text { pedido de impeachment. }\end{array}$ \\
\hline $06 / 04 / 2016$ & $\begin{array}{l}\text { O relator do pedido de impeachment, Deputado Jovair Arantes apresenta seu } \\
\text { relatório pela admissibilidade da denúncia. }{ }^{2}\end{array}$ \\
\hline $11 / 04 / 2016$ & $\begin{array}{l}\text { A Comissão Especial do Impeachment concluiu seus trabalhos e aprova, por 38 votos } \\
\text { a 27, o relatório do deputado Jovair Arantes (PTB-GO), no qual é recomenda a } \\
\text { abertura de processo contra a presidente da República, Dilma Rousseff. }\end{array}$ \\
\hline $12 / 04 / 2016$ & $\begin{array}{l}\text { O presidente da Câmara dos Deputados, Eduardo Cunha, anuncia que a sessão para } \\
\text { votar o processo de impeachment da presidente Dilma Rousseff durará 3 dias (sexta- } \\
\text { feira, sábado e domingo). }\end{array}$ \\
\hline $17 / 04 / 2016$ & $\begin{array}{l}\text { A Câmara dos Deputados autoriza instauração de processo de impeachment de Dilma } \\
\text { com 367 votos a favor, 137 contra e 7 abstenções em sessão de votação que durou } 6 \\
\text { horas. }\end{array}$ \\
\hline
\end{tabular}

${ }^{1}$ http://www.camara.gov.br/internet/agencia/pdf/Decis\%C3\%A30 sobre impeachment CD.pdf

${ }^{2}$ http://www2.camara.leg.br/atividade-legislativa/comissoes/comissoes-temporarias/especiais/55alegislatura/denuncia-contra-a-presidente-da-republica/documentos/outrosdocumentos/ParecerDep.JovairArantes.pdf 


\begin{tabular}{|c|c|}
\hline $18 / 04 / 2016$ & $\begin{array}{l}\text { A Câmara dos Deputados entrega relatório pela aprovação do processo de abertura } \\
\text { do impeachment ao Senado Federal. }\end{array}$ \\
\hline $26 / 04 / 2016$ & $\begin{array}{l}\text { O Senado Federal instala Comissão Especial relativa à autorização para o processo e } \\
\text { o julgamento da Presidente da República por suposto crime de responsabilidade. }\end{array}$ \\
\hline $04 / 05 / 2016$ & $\begin{array}{l}\text { O Senador Antonio Anastasia, relator do processo, apresenta seu relatório }{ }^{3} \text { que } \\
\text { recomenda a abertura do processo de afastamento da presidente Dilma Rousseff. }\end{array}$ \\
\hline $06 / 05 / 2016$ & $\begin{array}{l}\text { Por } 15 \text { votos a favor e } 5 \text { contra é aprovado o relatório recomendando a abertura do } \\
\text { processo de impeachment. }\end{array}$ \\
\hline $12 / 05 / 2016$ & $\begin{array}{l}\text { O relatório é submetido ao Plenário do Senado Federal e por } 55 \text { votos a favor e } 22 \\
\text { contra, o processo é formalmente instaurado (BRASIL, 2016a). }\end{array}$ \\
\hline $12 / 05 / 2016$ & A presidente Dilma Rousseff é afastada do exercício do cargo por 180 dias. \\
\hline $26 / 06 / 2016$ & Comissão especial termina de ouvir todas as testemunhas de defesa e acusação. \\
\hline $02 / 08 / 2016$ & $\begin{array}{l}\text { Novo parecer é apresentado e nele o relator o Senado Antonio Anastasia conclui que } \\
\text { as acusações são procedentes e a acusada deve ser levada a julgamento final pelo } \\
\text { Plenário do Senado Federal. }\end{array}$ \\
\hline $04 / 08 / 2016$ & $\begin{array}{l}\text { Comissão aprova o parecer do relator por } 14 \text { votos a favor e } 5 \text { contra levar a } \\
\text { presidente Dilma Rousseff ao julgamento final. }\end{array}$ \\
\hline $10 / 08 / 2016$ & $\begin{array}{l}\text { Por } 59 \text { votos a favor e } 21 \text { contra é aprovada a condução da presidente Dilma Rousseff } \\
\text { ao julgamento final. }\end{array}$ \\
\hline $31 / 08 / 2016$ & $\begin{array}{l}\text { Plenário do Senado Federal aprova o impeachment de Dilma Rousseff, por } 61 \text { votos a } \\
\text { favor e } 20 \text { contra. }\end{array}$ \\
\hline
\end{tabular}

Fonte: Elaborado pelo autor.

\section{Método da pesquisa}

De natureza descritiva e com abordagem quantitativa-qualitativa, a presente pesquisa teve como objeto empírico de estudo as notas taquigráficas ${ }^{4}$ individuais de cada discurso proferido pelos parlamentares, no momento da manifestação do voto a favor ou contrário à abertura do processo de impeachment, na sessão plenária da Câmara dos Deputados em 17 de abril de 2016. A escolha pelas notas taquigráficas se deu por serem, ao mesmo tempo, documentos oficiais de registro histórico do parlamento e por registrarem com precisão os discursos orais dos parlamentares.

O universo da pesquisa consistiu em 504 manifestações de voto, sendo 367 a favor e 137 contra. A análise do texto consistiu na identificação dos itens-chave para a representação dos discursos parlamentares, descartando-se possíveis ofensas, palavras descontextualizadas ou demais itens de menor relevância. A Figura 1 apresenta um exemplo de nota taquigráfica do voto de um parlamentar e o grifo nos itens que foram identificados como itens-chave durante a fala.

\footnotetext{
${ }^{3}$ http://www.senado.leg.br/atividade/rotinas/materia/getPDF.asp?t=192478\&tp=1

${ }^{4} \mathrm{~A}$ íntegra da sessão e todas as notas taquigráficas estão disponíveis em: https://www.camara.leg.br/internet/plenario/notas/extraord/2016/4/EV1704161400.pdf
} 
Figura 1. Nota taquigráfica.

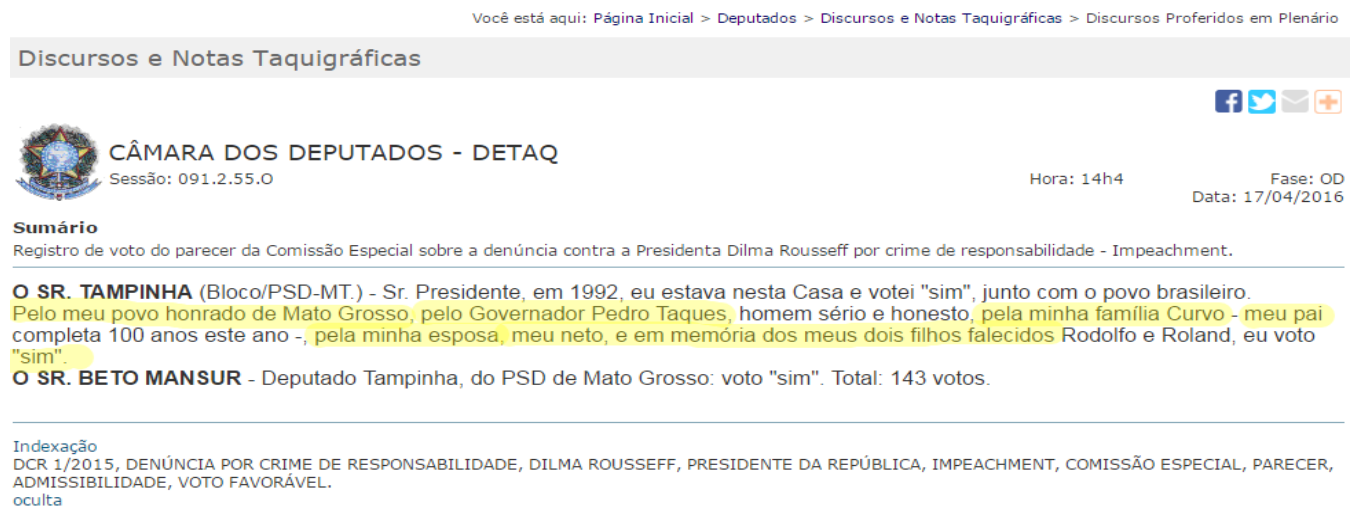

Fonte: Câmara dos Deputados, 2019.

Com todos os discursos analisados e estruturados, chegou-se ao número total de 1.348 itens-chave citados pelos parlamentares como identificadores dos discursos. Dividindo-se esse número pelo total de votantes, 504 deputados, chega-se à média de quase 3 itens-chave específicos por voto. Ao todo 141 deputados votantes, $27,97 \%$ do total, não utilizaram seu voto para fazer referência a algum item específico, apenas manifestaram sua posição a favor ou contrária. Levando-se em conta o tempo de duração da sessão de votação, 6 horas, observa-se que em média cada deputado levou quase 43 segundos para proferir seu discurso e voto. Dentro do conjunto de dados disponíveis nas notas taquigráficas foram selecionadas e organizadas em uma planilha ${ }^{5}$, as seguintes informações:

1. Nome do parlamentar;

2. Partido e Estado do parlamentar;

3. Endereço eletrônico do voto;

4. Campos para preenchimento dos itens-chave identificados;

5. Direcionamento do voto: sim ou não.

A Figura 2 apresenta a planilha com os respectivos dados preenchidos.

Figura 2. Planilha de análise.

\footnotetext{
${ }^{5} \mathrm{~A}$ planilha poder ser consultada no seguinte endereço: https://drive.google.com/open?id=1rsCl71J5fEKDXIRIFHP1ia6bavQ XbGXXdjnKuepTxs
} 


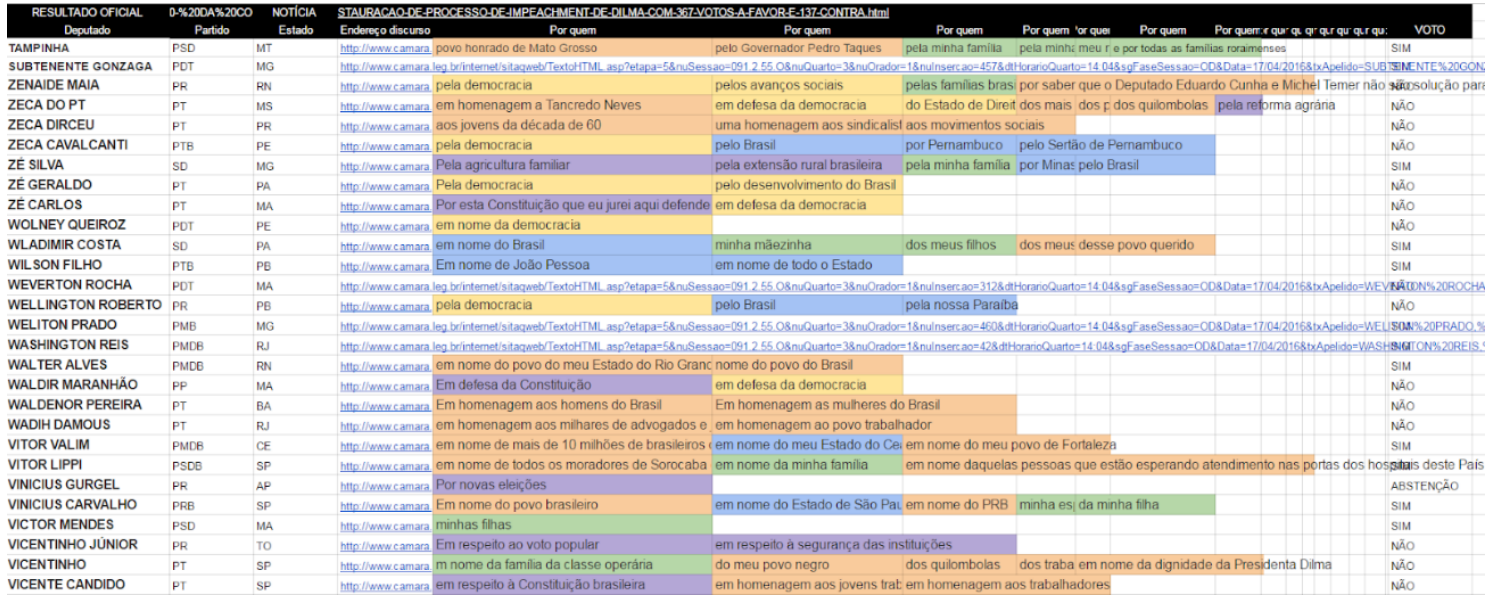

Fonte: Elaborada pelo autor.

Com a organização e análise dos dados pelos princípios da similaridade, diferenças e relação de sinonímia, foram criadas cinco macro categorias que agrupam os itens-chave identificados. São elas:

1. Família: contém menções a membros da família do parlamentar em vários graus de parentesco;

2. Valores: reúne citações a valores morais, políticos e sociais;

3. Pessoas/Classes/Instituições: reúne citações a pessoas, grupos específicos da sociedade, classes profissionais, organizações civis, políticas, instituições públicas e privadas;

4. Localidades: citação a municípios, cidades, regiões específicas, estados e ao país;

5. Objetos/Coisas/Ideias: agrupa menções feitas a itens que não se enquadravam em nenhuma das categorias anteriores.

\section{Discussão dos dados}

Em uma primeira análise sobre a característica dos votos proferidos no processo de análise da abertura do impeachment na Câmara dos Deputados, observa-se um fato interessante no tocante à coligação que elegeu Dilma Rousseff presidente. Entre os nove partidos que faziam parte da coligação "Com a força do povo", construída para as eleições de 2014, apenas os membros do PT (60 membros) e PC do B (10 membros) não votaram pela autorização da abertura do processo, logo seguindo a indicação da bancada e o princípio da fidelidade partidária (COSTAS, 2018). Já nos demais partidos da coligação, houve vários votos a favor da abertura do processo de impeachment. O Quadro 2 apresenta o número de votos favoráveis à abertura do processo de impeachment. 
Quadro 2. Divisão dos votos dentro da coligação "Com a força do povo".

\begin{tabular}{|l|c|c|}
\hline \multicolumn{1}{|c|}{ Partido } & Quantidade de votos possíveis & $\begin{array}{c}\text { Voto a favor para a } \\
\text { abertura do processo }\end{array}$ \\
\hline PMDB & 66 & 59 \\
\hline PSD & 37 & 29 \\
\hline PP & 42 & 38 \\
\hline PR & 36 & 26 \\
\hline PROS & 6 & 4 \\
\hline PDT & 18 & 6 \\
\hline PRB & 22 & 22 \\
\hline TOTAL & $\mathbf{2 2 7}$ & $\mathbf{1 8 4}$ \\
\hline
\end{tabular}

Fonte: Elaborado pelo autor.

Ao se analisar a orientação dos líderes partidários, que representa a indicação do partido em como cada deputado deve votar, percebe-se que novamente apenas os membros PT e PC do $B$ respeitaram a indicação partidária em desaprovar a abertura do processo de impeachment. O Quadro 3 apresenta os partidos de acordo com a orientação do líder partidário:

Quadro 3. Orientação dos líderes partidários.

\begin{tabular}{|l|l|}
\hline \multicolumn{1}{|c|}{ Partido } & \multicolumn{1}{c|}{ Orientação do líder do partido } \\
\hline PMDB & Liberação de bancada \\
\hline PSD & Voto contra o impeachment \\
\hline PP & Liberação de bancada \\
\hline PR & Voto contra o impeachment \\
\hline PROS & Liberação de bancada \\
\hline PDT & Voto contra o impeachment \\
\hline PRB & Voto pró-impeachment \\
\hline
\end{tabular}

Fonte: Elaborado pelo autor

Conforme pode ser verificado nos quadros 2 e 3 , partidos que faziam parte da base de sustentação da presidente Dilma Rousseff, votaram majoritariamente a favor da abertura do processo de impeachment ( $81 \%$ dos votos possíveis) e logo número expressivo de membros desobedecendo a orientação do líder do partido. Três partidos (PSD, PR e PDT) tinha como orientação voto contra impeachment, ou seja, exigiam de seus membros o voto "não" perfazendo um total de 91 votos. Desse total, 61 parlamentares votaram "sim", que representaram $67 \%$ de votos "infiéis" à orientação partidária, demonstrando a perda da base de apoio à presidente que já não se encontrava coesa e que havia discordância interna dentro dos próprios partidos quanto à decisão do voto.

Nas semanas posteriores ao processo de votação várias críticas surgiram a respeito da 
do conteúdo dos votos dos Deputados. De acordo com as críticas, houve um número elevado de citações direcionadas a pessoas ou familiares dos deputados, fato que denotaria descolamento da função do parlamentar enquanto representante da sociedade. A partir de uma contagem de palavras dos votos proferidos, o veículo de comunicação G1 Política construiu uma nuvem de tags onde a palavra "voto" seria o item mais usado nos votos. A Figura 3 apresenta a nuvem de tags apresentada na matéria com os termos mais utilizados pelos parlamentares.

Figura 3. Nuvem de tags dos itens dos discursos.

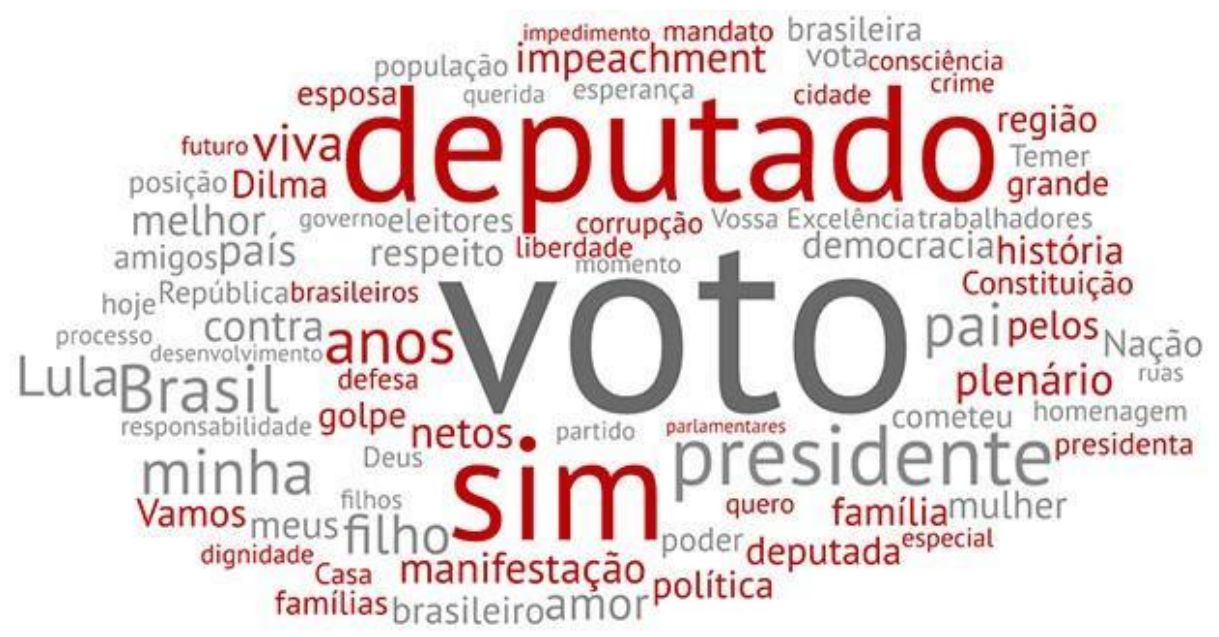

Fonte: G1 Política - http://g1.globo.com/politica/processo-de-impeachment-dedilma/noticia/2016/04/deus-filhos-veja-os-termos-mais-citados-na-votacao-doimpeachment.html

Embora uma nuvem de tags possua relevância para demonstração gráfica de determinado contexto, ela não é suficiente para demonstrar a representatividade de cada palavra dentro dos discursos por se apoiar em uma análise apenas quantitativa. Dessa maneira, para que fosse possível identificar a estrutura dos votos proferidos, a representatividade das palavras mencionadas e apoiando-se em uma abordagem qualitativa de análise dos discursos, foram identificados itens-chave para a caracterização e contextualização de cada voto. Desse processo surgem os seguintes dados:

1. O núcleo familiar ocupa a quarta posição entre as categorias mais citadas (238 citações no total), com forte concentração para citações a filhos (56 menções) e família no geral (81 menções), conforme pode ser visto no Quadro 4.

Quadro 4. Categoria Família.

\begin{tabular}{|l|r|}
\hline \multicolumn{2}{|c|}{ FAMÍLIA } \\
\hline \multicolumn{2}{|c|}{ Item-chave } \\
\hline Noras & Quantidade \\
\hline
\end{tabular}




\begin{tabular}{|l|r|}
\hline Bisnetos (as) & 1 \\
\hline Sobrinhos(as) & 2 \\
\hline Avós & 2 \\
\hline Irmãos(as) & 3 \\
\hline Netos(as) & 22 \\
\hline Cônjuge & 23 \\
\hline Pais & 28 \\
\hline Família brasileira (famílias estaduais, famílias desempregadas, famílias genéricas, \\
família evangélica inclusas & 56 \\
\hline Filhos(as) & 81 \\
\hline Família própria & 238 \\
\hline TOTAL & 236 \\
\hline
\end{tabular}

Fonte: Elaborado pelo autor.

2. A categoria Valores é a terceira mais citada (246 citações no total), é a que apresenta uma dispersão maior de menções (55 tipos diferentes), baixo acúmulo de menções em um único item, tendo a democracia como o valor citado mais vezes com 64 menções. O Quadro 5 apresenta o número de ocorrências.

Quadro 5. Categoria Valores.

\begin{tabular}{|l|r|}
\hline \multicolumn{2}{|c|}{ VALORES } \\
\hline \multicolumn{2}{|c|}{ Item-chave } \\
\hline Soberania popular & 1 \\
\hline Igualdade & 1 \\
\hline Fraternidade & 1 \\
\hline Verdade & 1 \\
\hline Lealdade & 1 \\
\hline Harmonia & 1 \\
\hline Concórdia & 1 \\
\hline Cidadania & 1 \\
\hline Responsabilidade & 1 \\
\hline Decência & 1 \\
\hline Nova ordem política & 1 \\
\hline Contra violência & 1 \\
\hline Avanço social & 1 \\
\hline Reforma & 1 \\
\hline Independência (poderes) & 1 \\
\hline
\end{tabular}




\begin{tabular}{|c|c|}
\hline Seriedade & 1 \\
\hline Bons costumes & 1 \\
\hline Transparência & 1 \\
\hline Credibilidade (política, social) & 1 \\
\hline Impessoalidade & 1 \\
\hline Publicidade & 1 \\
\hline Eficiência & 1 \\
\hline Educação & 1 \\
\hline Vida & 1 \\
\hline Autoestima & 1 \\
\hline Solidariedade & 1 \\
\hline Segurança & 1 \\
\hline União & 1 \\
\hline Honra & 1 \\
\hline Reconstrução & 1 \\
\hline País melhor & 2 \\
\hline Defesa da vida & 2 \\
\hline Honestidade & 2 \\
\hline Saúde & 2 \\
\hline Consciência & 2 \\
\hline História pessoal & 2 \\
\hline Paz & 2 \\
\hline Religião & 3 \\
\hline Mudança & 3 \\
\hline Dignidade (humana) & 3 \\
\hline Coerência & 3 \\
\hline Ética & 4 \\
\hline Justiça & 4 \\
\hline Nação (liberdade, união, bem, defesa) & 5 \\
\hline Legalidade (respeito às leis, coronéis) & 7 \\
\hline Moralidade (boquinha do PT e PCdoB incluso, vagabundização) & 8 \\
\hline Crescimento econômico & 8 \\
\hline Amor (pessoas, pátria, país, bandeira, à vida, eleitores) & 9 \\
\hline Liberdade & 10 \\
\hline Desenvolvimento (nação, país, Estado) & 10 \\
\hline Direito (Estado de direito, direito à/ao, individual) & 12 \\
\hline Combate à corrupção (fim, contra, réus lava-jato e mensalão) & 15 \\
\hline Esperança & 17 \\
\hline Futuro (país, crianças, melhor) & 17 \\
\hline
\end{tabular}




\begin{tabular}{|l|r|}
\hline Democracia (Estado democrático, instituições democráticas) & 64 \\
\hline TOTAL & 246 \\
\hline
\end{tabular}

Fonte: Elaborado pelo autor.

3. A categoria Pessoas/Classes/Instituições é a mais citada (452 citações no total), quantidade elevada de menções (42 tipos diferentes) com predominância de "povo brasileiro" como o item mais citado (195 vezes). Nessa categoria embora haja a possibilidade de registrar os nomes citados, se optou apenas por registrar os nomes das seguintes pessoas fortemente identificadas com a questão do impeachment: Luís Inácio Lula da Silva (2 citações), Dilma Rousseff (10 citações), juiz Sérgio Moro (1 citação), vice-presidente Michel Temer (1 citação), Eduardo Cunha (1 citação). O Quadro 6 apresenta o número de ocorrências.

Quadro 6. Categoria Pessoas/Classes/Instituições.

\begin{tabular}{|c|c|}
\hline \multicolumn{2}{|c|}{ PESSOAS/CLASSES/INSTITUIÇÕES } \\
\hline Item-chave & Quantidade \\
\hline Advogados & 1 \\
\hline Sérgio Moro & 1 \\
\hline Administração pública & 1 \\
\hline Sistema Único de Saúde & 1 \\
\hline Frente parlamentar & 1 \\
\hline Agricultores & 1 \\
\hline Michel Temer & 1 \\
\hline Eduardo Cunha & 1 \\
\hline Maçons & 1 \\
\hline Povo latino-americano & 1 \\
\hline Sindicatos (sindicalista incluso) & 1 \\
\hline Morador de rua & 1 \\
\hline Professores & 1 \\
\hline Universidades & 1 \\
\hline Lula & 2 \\
\hline Aposentados & 2 \\
\hline Fundações, Organizações sociais & 2 \\
\hline Índios & 2 \\
\hline LGBT & 2 \\
\hline Portador necessidade especial & 2 \\
\hline Crianças & 3 \\
\hline
\end{tabular}




\begin{tabular}{|c|c|}
\hline Programas sociais (Pronatec, Mais médicos, minha casa minha vida) & 3 \\
\hline Forças Armadas & 3 \\
\hline Médicos & 4 \\
\hline Deus/Jesus & 4 \\
\hline Polícia & 4 \\
\hline Militares & 5 \\
\hline Desempregados & 7 \\
\hline Mulheres & 9 \\
\hline Negros (Zumbi, Dandara, quilombolas) & 9 \\
\hline Futuras e atuais gerações & 9 \\
\hline Dilma & 10 \\
\hline Amigos & 10 \\
\hline Movimentos Sociais & 11 \\
\hline Jovens & 12 \\
\hline Religiosos & 12 \\
\hline Partidos políticos & 16 \\
\hline Políticos & 31 \\
\hline Trabalhador (rural ou da cidade) & 33 \\
\hline Eleitores & 36 \\
\hline Povo brasileiro (menção à pessoa dos Estados também, cidadão) & 195 \\
\hline TOTAL & 452 \\
\hline
\end{tabular}

Fonte: Elaborado pelo autor

4. A categoria Localidades é a segunda mais citada (344 citações no total) é a menor em quantidade de tipos (4 tipos diferentes), com distribuição relativamente homogênea de citação com exceção do tipo "região" que recebeu apenas 19 menções. O Quadro 7 apresenta o número de ocorrências.

Quadro 7. Categoria Localidades.

\begin{tabular}{|l|r|}
\hline \multicolumn{2}{|c|}{ LOCALIDADES } \\
\hline \multicolumn{1}{|c|}{ Item-chave } & Quantidade \\
\hline Regiões & 19 \\
\hline Cidades/Municípios & 87 \\
\hline
\end{tabular}




\begin{tabular}{|l|r|}
\hline País & 105 \\
\hline Estados (Distrito Federal incluso) & 133 \\
\hline TOTAL & 344 \\
\hline
\end{tabular}

Fonte: Elaborado pelo autor

5. A categoria Objetos/Coisas/Ideais foi a categoria que recebeu o menor número de menções (68 no total) com dispersão considerável nos tipos citados e possui a Constituição (30 menções) como o item mais citado. O Quadro 8 apresenta os dados.

Quadro 8. Categoria Objetos/Coisas/Ideias.

\begin{tabular}{|c|c|}
\hline \multicolumn{2}{|c|}{ OBJETOS/COISAS/IDEIAS } \\
\hline Item-chave & Quantidade \\
\hline Extensão rural & 1 \\
\hline Segurança instituições & 1 \\
\hline Contra o golpe & 1 \\
\hline Ordenamento jurídico & 1 \\
\hline Estatuto desarmamento & 1 \\
\hline Transportes & 1 \\
\hline Reforma urbana & 1 \\
\hline Cooperativismo & 1 \\
\hline Reforma política & 1 \\
\hline Bandeira nacional & 1 \\
\hline Agropecuária & 1 \\
\hline Eleições & 2 \\
\hline Emprego & 2 \\
\hline Sonhos & 2 \\
\hline Indústria nacional & 2 \\
\hline Ciência e tecnologia & 2 \\
\hline Pré-sal & 2 \\
\hline Agricultura familiar & 3 \\
\hline Reforma agrária & 5 \\
\hline Voto popular & 7 \\
\hline Constituição & 30 \\
\hline TOTAL & 68 \\
\hline
\end{tabular}

Fonte: Elaborado pelo autor.

Conforme pode ser observado nos dados apresentados nos quadros 4 a 8 , o item-chave 
mais citado, ou seja, o termo que os deputados mais utilizaram não estava na categoria família ou algo referente a sua vida particular. O item-chave mais mencionado foi "povo brasileiro" presente em 195 votos e pertencente à categoria "Pessoas/Classes/Instituições". Ao se fazer uma comparação numérica, "povo brasileiro" possui quase a mesma quantidade de menções que a categoria família, mais menções do que a categoria objetos/coisas/ideais e sozinho, o item-chave "povo brasileiro" representa $79 \%$ da categoria valores e mais de $50 \%$ de toda a categoria localidades.

\section{Conclusão}

Quase 200 anos de existência como uma nação independente, fazem do Brasil um país jovem, propício a fomentar discussões e reviravoltas quanto à sua organização enquanto Estado. Princípio fundamental na ideia de democracia, a alternância dos representantes, é feita pelo mecanismo mais forte de manifestação do desejo da sociedade: o voto. No entanto, ele não é a única maneira disponível para provocar uma mudança na posição de chefe de um Poder.

O processo de impeachment, utilizado pela segunda vez no Brasil, apresenta-se como via alternativa para que a sociedade ou o próprio Estado possa realizar a troca de seus representantes. Esse processo, geralmente longo, extraordinário e que demanda uma grande energia da instituição responsável pelo julgamento, o Congresso Nacional, altera significativamente toda a uma estrutura de governo erigida e principalmente coloca a própria sociedade rumo a um futuro permeado por incertezas. O processo de impeachment é uma ruptura da normalidade e procedimentos dentro de uma democracia, por isso deve ser utilizado como último recurso para provocar uma alternância de poder ou troca de representantes eleitos.

Embora o processo de julgamento seja de competência das Casas Legislativas, os meios de comunicação e a informação necessária na tomada de decisão possuem também responsabilidade nesse evento, inclusive no tocante a serem a ponte entre sociedade e o parlamento durante todo o processo de impeachment. Nessa incumbência, nobre e árdua, cabe aos atores informacionais agiram de maneira transparente, equilibrada e serena quanto à divulgação, organização e disseminação dos fatos com o objetivo de apresentar para a sociedade as informações de maneira correta, fidedigna e imparcial.

Sendo assim, a sociedade brasileira se comporta como cliente e ao mesmo tempo objeto das informações geradas dentro de um processo de impeachment, que envolve além de situações legais, interesses pessoais e ideários políticos, conjunto de itens que são bastante afetados e suscetíveis à interferências que podem conduzir à dificuldade ou obscurecimento dos fatos e o próprio entendimento real desse evento jurídico-político tão importante para a 
democracia e que envolve o poder Legislativo, um dos poderes mais sensíveis à opinião pública e que carrega consigo a alcunha de ser o ente com maior índice de desconfiança e descrédito perante a sociedade (CINNANTI, 2011).

Tendo esses fatos como premissas a presente pesquisa visou entender o contexto informacional que fundamentou ou justificou a posição dos deputados no momento de seus votos. Conforme foi possível verificar, os dados coletados e as análises realizadas demonstram que na retórica parlamentar durante a manifestação da posição dos parlamentares ante a autorização de abertura de processo de impeachment contra a presidente Dilma Rousseff, embora haja menções a pessoas de seu círculo pessoal ou com ligações afetivas nos discursos, o item-chave identificado pela análise qualitativa dos votos, sejam eles a favor ou contra, foi "povo brasileiro".

Essa expressão, em linhas gerais, é utilizada para representar a coletividade da sociedade brasileira que tem o Estado brasileiro como condutor das políticas públicas. Seja pelo grande impacto eleitoral ou por ter sido uma sessão com grande visibilidade nos veículos de comunicação e no debate da sociedade, a coleta de dados permite inferir que os deputados de forma planejada ou autêntica, explicitaram em seus votos uma série de itens e que desses sobressai um conceito relacionado ao interesse coletivo. A análise qualitativa dos discursos permitiu identificar itens definidores dos votos para além da quantificação de uso de determinada palavra, que por diversas vezes não significa ser o item chave de um discurso.

Perante a limitação dos dados analisados e apesar de não ser objeto desse estudo, ainda assim, foi possível verificar, ainda que superficialmente, a questão da fidelidade partidária dos parlamentares, já que os dados apontam ter havido um número expressivo de votos favoráveis ao impeachment provenientes da coligação partidária que foi a base de sustentação da presidente Dilma Rousseff e, consequentemente, tais votos foram contrários à orientação partidária, dessa forma reforçando a percepção que o posicionamento dos deputados foi influenciado por suas decisões pessoais. Os únicos partidos que mantiveram coesão de votos e orientação partidária foi o Partidos dos Trabalhadores (PT), partido da presidente Dilma Rousseff e o Partido Comunista do Brasil (PCdoB), ao registrarem 100\% dos votos contrários ao impeachment, conforme orientação partidária.

Apesar de se tratar de uma arena de debate político, onde as manifestações das ideias tendem a ser difusas em conteúdo e forma, observou-se que existe um padrão de posicionamento dos votos em relação a pessoas ou grupos de pessoas, de determinada localidade com a adição de algum valor moral ou ético na decisão do voto do parlamentar. Exatamente decorrente disso que as categorias referentes a esses itens foram as com maior número absoluto de menções.

De maneira conclusiva, é possível ponderar que o contexto informacional que 
fundamentou o discurso parlamentar orbitou em torno de itens relacionados ao coletivo, mesmo com a existência de palavras e menções a familiares e questões particulares dos parlamentares.

\section{Referências}

ARAÚJO JÚNIOR, Rogério Henrique de. Precisão no processo de busca e recuperação da informação. Brasília: Thesaurus, 2007. 176 p.

BAPTISTA, Dulce Maria. A relevância do texto na organização e representação da informação. In: BAPTISTA, Dulce Maria; ARAÚJO JÚNIOR, Rogério Henrique de (org.). Organização da informação: abordagens e práticas. Brasília: Thesaurus, 2015. p. 21-43.

BARROS, Mariana. O arrastão da Lava-Jato. Veja, v. 49, n. 12, p. 64-68, 23 mar. 2016.

BICUDO, Hélio Pereira; REALE JÚNIOR, Miguel; PASCHOAL, Janaína Conceição; PEREIRA, Flávio Henrique Costa. Denúncia por crime de responsabilidade n. 1/2015. Diário da Câmara dos Deputados, n. 35, Suplemento, tomo 1, p. 4-5340, 18 mar. 2016. Disponível em:

http://imagem.camara.gov.br/Imagem/d/pdf/DCD0020160318S00350000.PDF\#page= Acesso em: 3 maio 2020.

BOBBIO, Norberto. Igualdade e liberdade. Rio de Janeiro: Ediouro, 1996. 96 p.

BRASIL. Câmara dos Deputados. Discursos e notas taquigráficas. Disponível em: http://www.camara.leg.br/internet/sitaqweb/TextoHTML.asp?etapa=5\&nuSessao=09 1.2.55.0\&nuQuarto $=3 \&$ nuOrador $=1 \&$ nulnsercao $=224 \& \mathrm{dt}$ thorarioQuarto $=14: 04 \&$ sgFas eSessao=OD\&Data=17/04/2016\&txApelido=TAMPINHA,\%20PSDMT\&txFaseSessao=Ordem\%20do\%20Dia\&txTipoSessao=Deliberativa\%20Extraordin\%C 3\%A1ria\%20-\%20CD\&dtHoraQuarto=14:04\&txEtapa=\# Acesso em: 3 maio 2020.

BRASIL. Senado Federal. Impeachment: o julgamento da Presidente Dilma Rousseff pelo Senado Federal. Brasília: Senado Federal, SAJS, 2016. 659 p.

BRASIL. Senado Federal. 20 horas na história: a longa sessão de admissibilidade do impeachment da Presidente Dilma Rousseff: 11 e 12 de maio de 2016, 55a legislatura, 2a sessão legislativa ordinária, 71a sessão deliberativa extraordinária. Brasília: Senado Federal, 2016a. 333 p.

BRASIL. Senado Federal. Ofício SGM/P n. 1388, da Mesa da Câmara dos Deputados, autorizando o Senado Federal a Instaurar Processo contra o Excelentíssimo Senhor Presidente da República Fernando Affonso Collor de Mello, por Crime de Responsabilidade. Brasília: Senado Federal, 1992. 696 p.

BRASIL. Constituição (1988). Constituição da República Federativa do Brasil. 35. ed. Brasília: Edições Câmara, 2012. 
BRASIL. Tribunal Superior Eleitoral. Estatísticas eleitorais 2014. Disponível: http://www.tse.jus.br/eleicoes/estatisticas/estatisticas-candidaturas2014/copy of estatisticas-eleitorais-2014 Acesso em: 3 maio 2020.

CARLOMAGNO, Márcio C.; ROCHA, Leonardo C. Como criar e classificar categorias para fazer análise de conteúdo: uma questão metodológica. Revista Eletrônica de Ciência Política, v. 7, n. 1, p. 173-188, 2016. Disponível em: https://revistas.ufpr.br/politica/issue/view/2181 Acesso em: 3 maio 2020.

CHARAUDEAU, Patrick. Discurso político. 2. ed. São Paulo: Contexto, 2013. 328 p.

CINNANTI, Cristina Jacobson Jácomo. A (des)confiança do cidadão no poder Legislativo e a qualidade da democracia no Brasil. E-legis, n. 6, p. 84-95, 2011. Disponível em: http://e-legis.camara.leg.br/cefor/index.php/e-legis/article/view/73 Acesso em: 3 maio 2020.

COSTA, Ricardo Sérvulo Fonseca da. Fidelidade versus mandato livre: a disciplina partidária como obstáculo à responsividade do parlamentar. In: FUX, Luiz; PEREIRA, Luiz Fernando Casagrande; AGRA, Walber de Moura (coord.). Tratado de direito eleitoral. Belo Horizonte: Fórum, 2018, v. 2, p. 161-177.

FAUSTO, Boris. História concisa do Brasil. 2. ed. São Paulo: Edusp, 2014. 324p.

GALUPPO, Marcelo Campos. Impeachment: o que é, como se processa e por que se faz. Belo Horizonte: D’Plácido, 2016. 270 p.

GALVÃO, Carlos Fernando; MEFFE, Corinto. Democracia: do conceito à prática; da representação à participação. São Paulo: Claridade, 2010.110 p.

GOYARD-FABRE, Simone. O que é democracia?. São Paulo: Martins Fontes, 2003. 365 p.

LANCASTER, Frederick W. Indexação e resumos: teoria e prática. Brasília: Briquet de Lemos, 2004. 452 p.

LANGRIDGE, Derek. Classificação: abordagem para estudantes de biblioteconomia. Rio de Janeiro: Interciência, 2006. 120 p.

LE COADIC, Yves-François. A ciência da informação. 2. ed. Brasília: Briquet de Lemos Livros, 2004. 124 p.

LIMA, Gercina Ângela Borém de Oliveira. Modelos de categorização: apresentando o modelo clássico e o modelo de protótipos. Perspectivas em Ciência da Informação, v. 15 , n. 2, p. 108-122, maio/ago. 2010. Disponível em: http://www.scielo.br/pdf/pci/v15n2/a08v15n2 Acesso em: 3 maio 2020.

MACIEL, Maria Lucia; ALBAGLI, Sarita (org.). Informação, conhecimento e poder: mudança tecnológica e inovação social. Rio de Janeiro: Garamond, 2011. 332 p. 
MENDES, Gilmar Ferreira; BRANCO, Paulo Gustavo Gonet. Curso de direito constitucional. 11. ed., rev. e atual. São Paulo: Saraiva, 2016.1504 p.

MOREIRO GONZÁLEZ, José Antonio. Linguagens documentárias e vocabulários semânticos para a web: elementos conceituais. Salvador: EDUFBA, 2011. 128 p.

MORENO, Fernanda Passini. Da representação descritiva como área de pesquisa e sua relação com a recuperação da informação. In: BAPTISTA, Dulce Maria; ARAÚJO JÚNIOR, Rogério Henrique de (org.). Organização da informação: abordagens e práticas. Brasília: Thesaurus, 2015. p. 94-113.

ORLANDI, Eni. Análise de discurso: princípios e procedimentos. Campinas: Pontes, 2007.

PINTO, Céli Regina Jardim. Elementos para uma análise de discurso político. Barbarói, $n$. 24, 2006, p. 78-109. Disponível em: https://online.unisc.br/seer/index.php/barbaroi/article/view/821/605 Acesso em: 3 maio 2020.

REALE JÚNIOR, Miguel. Triste aniversário. O Estado de São Paulo, n. 44426, p. A2, 6 jun. 2015.

ROWLEY, Jennifer. A biblioteca eletrônica. 2. ed. Brasília: Briquet de Lemos, 2002. 399 p.

SCHIESSL, Marcelo; SHINTAKU, Milton. Sistemas de organização do conhecimento. In: ALVARES, Lillian (org.). Organização da informação e do conhecimento: conceitos, subsídios interdisciplinares e aplicações. São Paulo: B4 Ed., 2012. p. 49-118.

SOUZA, Sebastião de. CDU: como entender e utilizar a 2a edição-padrão internacional em língua portuguesa. 3. ed. Brasília: Thesaurus, 2012. 160 p.

TOCQUEVILLE, Alexis de. A democracia na América. São Paulo: Folha de São Paulo, 2010. $324 \mathrm{p}$. 